\title{
Computational Thinking among High School Students
}

\author{
Nur Iwani Zakaria, Zanaton H. Iksan* \\ Faculty of Education, Universiti Kebangsaan Malaysia, Bangi, 43600, Selangor, Malaysia
}

Received August 2, 2020; Revised October 7, 2020; Accepted October 30, 2020

\section{Cite This Paper in the following Citation Styles}

(a): [1] Nur Iwani Zakaria, Zanaton H. Iksan, "Computational Thinking among High School Students," Universal Journal of Educational Research, Vol. 8, No. 11A, pp. 9 - 16, 2020. DOI: 10.13189/ujer.2020.082102.

(b): Nur Iwani Zakaria, Zanaton H. Iksan (2020). Computational Thinking among High School Students. Universal Journal of Educational Research, 8(11A), 9 - 16. DOI: 10.13189/ujer.2020.082102.

Copyright $\odot 2020$ by authors, all rights reserved. Authors agree that this article remains permanently open access under the terms of the Creative Commons Attribution License 4.0 International License

\begin{abstract}
Computational thinking is a set of $21^{\text {st }}$ century skills that can be applied in problem-solving processes and daily activities. The significance of computational thinking skills in the $21^{\text {st }}$ century has opened educators' eyes and minds to apply these skills to teaching and learning processes. Therefore, a survey was conducted to identify the level of computational thinking skill among high school students and the difference in computational thinking in terms of students' gender and education level. Ultimately, 343 students from secondary schools around the Pasir Mas district in Malaysia were selected as respondents using the cluster sampling method. Data obtained were analyzed using descriptive statistics (i.e., mean score and standard deviation) and inferential statistics (i.e., $t$-test). The findings show that students' computational thinking skill is at a high level. In terms of gender comparison, female students' computational thinking skill is higher than that of male students. In addition, students' computational thinking skill by level of education is the same. Thus, teachers should emphasize computational thinking skills in teaching and learning processes, whether through computer-based or unplugged activities. Proactive measures are needed to improve students' level of computational thinking skills so that students equip themselves with the basic skills to face the challenges of the $21^{\text {st }}$ century.
\end{abstract}

Keywords Computational Thinking, Problem Solving, Creativity, Algorithm, Critical Thinking

\section{Introduction}

The advent of supercomputers, robotics, automation vehicles, neurotechnology advances, and genetic editing that helped individuals optimize their mental abilities marked the development of the fourth industrial revolution [1]. The rapid advancement of these technologies indicated a convergence of the priorities in the field of education given to the effectuation of $21^{\text {st }}$-century skills. As such, the integration of science, technology, engineering, and math (STEM) education in teaching and learning is gaining prominence and importance in the education system in Malaysia.

The $21^{\text {st }}$-century job market desperately needs skilled manpower equipped with problem-solving skills, creative and innovative thinking, and team players [2]. STEM education is one way to produce the required skilled manpower. The implementation of STEM educational methods that involve active learning, which indirectly incorporates the application of $21^{\text {st }}$-century skills, especially digital literacy aspects, will expose students to careers in the science and technology field, thereby preparing and increasing the amount of skilled manpower for the job market.

Computational thinking comprises a set of $21^{\text {st }}$-century basic skills that are applied in solving problems in daily life, including basic skills for analytical thinking, such as mathematical thinking, engineering thinking, and science thinking [3]. Computational thinking also has the potential to sharpen critical and creative thinking skills in designing technology tools and problem-solving processes [4,5]. Therefore, with the emergence of various job opportunities that are closely linked to computing in today's digital age, it is necessary to equip students with computational thinking skills.

The implementation of STEM education teaching methods requires students to solve problems through 
discovery and exploration. According to Yagci [6], this method helps students to master computational thinking skills (e.g., problem-solving techniques, creativity techniques, algorithmic thinking techniques, cooperative learning techniques, and critical thinking), which are essential to ensure that learning objectives are achieved. Therefore, teachers must know the level of students' computational thinking skills in order to design and implement teaching methods that give meaning and impact to students. This research examined the level of computational thinking among high school students.

Yadav et al. [4] found that women are currently not gaining enough attention or opportunities in STEM fields, indicating a lack of balance in the involvement of males and females. To avoid gender discrimination, this gap should be minimized. Previous studies have demonstrated that, in terms of computational thinking skills, no differences exist between male and female students [7,8], but the gender differences are inconsistent [7]. To achieve the same computational thinking skill level as males, females usually require additional training sessions [7], even though these skills encourage women to pursue careers in STEM fields. The study by Djambong and Freiman [9] also reported that level of computational thinking varies by educational level, which includes different technology access. Therefore, there is a need to study the level of computational thinking skills in terms of both gender and education level, as both men and women have a common interest in improving their computational thinking skills.

STEM education involves teaching and learning activities by implementing and applying four key areasscience, technology, engineering, and mathematics - in the real-world context. Its implementation is carried out using a variety of strategies, such as problem-, project-, game-, and inquiry-based learning [10-12]. This STEM education approach involves a more realistic and practical way of learning as it focuses more on hands-on activities that enhance thinking ability and problem solving [10]. At the same time, the STEM education learning strategy also has the potential to train students in applying $21^{\text {st }}$-century skills, particularly in the area of digital literacy, by emphasizing the concept of designing projects to solve real-world problems [2,13,14].

Recent studies have identified various definitions of computational thinking, yet scholars are still unable to reach an agreement on a singular definition. Nevertheless, scholars generally agree that computational thinking is a very important set of skills and is used to solve difficult problems in human life $[3,1,15,16]$. Computational thinking is a broad concept, and its application helps develop thinking skills so individuals can be more creative and think critically, especially in problem solving.

Barr and Stephenson[16] concluded that computational thinking is a problem-solving process involving several steps: (i) formulate a specific problem that involves the use of a computer or other device as a tool for solving the problem; (ii) organize, analyze, and represent data through the use of abstraction as a model or simulation; (iii) understand the problem using an algorithm; (iv) organize and analyze data logically; (v) identify, analyze, and apply several possible ways to determine the most effective combination of solutions; and (vi) generalize and use effective solution processes for other similar problems. Based on these steps, computational thinking consists of several components. Even so, the components found by Wing [3] are the most relevant and widely accepted by factors: problem solving, algorithm thinking, critical thinking, cooperative learning, and creative thinking [17].

Gelbal [18] interpreted the problem as all the things that confuse and give challenge to humans in daily life. Each individual has a different problem-solving strategy, depending on the level of that individual's problem-solving skills. In order to apply problem-solving skills, structured and systematic learning must be done by practicing basic skills. According to Mayer [19], a common step in problem-solving skills is to analyze each problem using the cognitive skills needed to solve the problem and then apply those skills systematically until proficient.

The concept of an algorithm is now widely used in various fields involving processes that require certain procedures, protocols, or techniques. The term algorithm refers to a set of steps or sequences to ensure that work or information is performed in an organized manner using the skills of understanding, applying, evaluating, and generating a new algorithm [20,21]. Algorithmic thinking skills have the potential to enhance an individual's ability to process information more efficiently as well as develop the ability to think in more detail and focus.

Critical thinking is one of the elements of higher-order thinking. The definition of critical thinking by Halpern [22] is the utilization of cognitive skills or techniques to promote the likelihood of a preferred behavior. Critically minded individuals are able to follow and apply every change in information efficiently [23]. Critical thinking is also defined as an active, ordinary, and meaningful process that can be used to leverage an individual's understanding and skills or the ideas and thoughts of others [24].

Slavin [25] states that cooperative learning refers to students' cooperation in small group learning, where an individual student's performance is evaluated based on group development and performance. Cooperative learning is one of the efficient ways of learning due to its contribution to students' academic achievement, information sharing, and the development of social skills between students [26]. This method also helps students achieve the maximum level of learning as students with different abilities and strengths cooperate in a small group to attain the same goals.

The concept of creativity encompasses different perspectives from different societies. Korkmaz et al. [27] stated that creativity is a skill in producing products that are 
not in the market yet or a new product, capable of imagining or performing work that is different from others' thinking as well as capable of generating new ideas. Sternberg and Lubart [28] viewed creativity as the potential to create something new and useful for the public; it also helps individuals solve everyday problems and access new and original information.

As computational thinking is expected to be one of the fundamental skills required for every individual in the $21 \mathrm{st}$ century and STEM education, which emphasizes learning strategies based on real-world problem solving, requires students to master and apply computational thinking skills, students' level of computational thinking skills needs to be evaluated to determine the extent to which students master these skills. This study discusses the level of computational thinking among students and their differences in terms of gender and education level. The results are expected to help teachers plan more effective teaching and learning methods after determining students' computational thinking levels.

\section{Materials and Methods}

This study was conducted using a quantitative research method. The researchers conducted a survey using questionnaires to determine the level of computational thinking among students. However, due to difficulties in identifying the exact number of the population, the cluster sampling method was used. Three out of 20 national secondary schools located in the Pasir Mas district in Malaysia were randomly selected to obtain samples for this study. All students in the three chosen schools were heterogeneous. A total of $n=343$ upper-form and lowerform students participated as respondents of this study. This sample was chosen because these students have gained exposure to computational thinking through the subject of computer science.

The questionnaire used to gather data was adapted from Yağcı [6]; its validity and reliability have been tested. A questionnaire was chosen as the instrument for data collection because of its effectiveness in obtaining accurate data from a large number of respondents as well as being easier to administer and analyze. The questionnaire consists of two sections: Part A and Part B. Part A includes questions about respondents' demographic characteristics whereas Part B asks about students' level of computational thinking skills - namely, problem-solving techniques (16 items), cooperative learning and critical thinking (5 items), creativity techniques (9 items), and algorithmic thinking techniques (4 items).

A 5-point Likert scale (strongly disagree $=1$, strongly agree $=5$ ) was used to determine each item's score. Data were then analyzed using a descriptive analysis (mean and standard deviation). The interpretation of each construct was divided into three levels (i.e., low, medium, high). The mean interpretation used in this study is based on a study by Lapammu and Mahamod [29], as shown in Table 1.

Table 1. Mean interpretation

\begin{tabular}{cc}
\hline Mean Range & Interpretation \\
\hline $1.00-2.33$ & Low \\
$2.34-3.67$ & Medium \\
$3.68-5.00$ & High \\
\hline
\end{tabular}

The instrument used in this study was also reviewed and validated by experts in the field of information, communication and technology (ICT) and STEM education. A pilot study was conducted with 30 students to determine the reliability of the instrument used. The pilot study participants had the same characteristics as those in the main study. Fifteen students each from the lower form and upper form were randomly selected as respondents. An analysis using Cronbach's alpha was conducted (see Table 2). According to Fraenkel [30], the reliability value of the instrument (i.e., Cronbach's alpha) must be at least 0.70 to be acceptable for use in research. The Cronbach's alpha value analysis shows that overall the instrument used was reliable (Cronbach's alpha $=0.899)$. As it has high validity and reliability, the data obtained from this study are more accurate and reliable.

Table 2. Cronbach's alpha value for each construct.

\begin{tabular}{ccc}
\hline Construct & $\begin{array}{c}\text { Number of } \\
\text { Items }\end{array}$ & $\begin{array}{c}\text { Cronbach's Alpha } \\
\text { Value }\end{array}$ \\
\hline $\begin{array}{c}\text { Problem Solving } \\
\text { Cooperative Learning \& }\end{array}$ & 16 & 0.866 \\
Critical Thinking & 5 & 0.725 \\
Creativity & 9 & 0.803 \\
Algorithmic Thinking & 4 & 0.751 \\
\hline
\end{tabular}

\section{Results}

Data were analyzed both descriptively and inferentially. The descriptive analysis, involving the mean value and standard deviation, was carried out to identify students' computational thinking level. Meanwhile, the inferential statistical analysis used the $t$-test of two independent samples to identify differences in students' level of computational thinking based on gender and education level. To determine the parametric or non-parametric nature of data, some $t$-test assumptions were considerednamely, data should be approximately distributed, and the homogeneity of variances has been reviewed and complied with before conducting the $t$-test.

Normality tests and histograms were used to ensure that the data were normally distributed. The results of the normality test analysis showed that the significant value for the Kolmogorov-Smirnov test was $\mathrm{p}=0.200$, which is $\mathrm{p}>$ 0.05 . Therefore, the data are considered to be normally distributed. The data distribution of students' computational thinking level is shown in Figure 1. The 
Levene test was conducted to determine the homogeneity of the variance. The test results show that the significant value for the variable of gender is $p=0.739$, which is $p>0.05$, indicating that the homogeneity of the variance is met. As for the education level variable, the homogeneity of the variance is $\mathrm{p}=0.012$, which is $\mathrm{p}<0.05$, so a separate $t$ variance test is used.

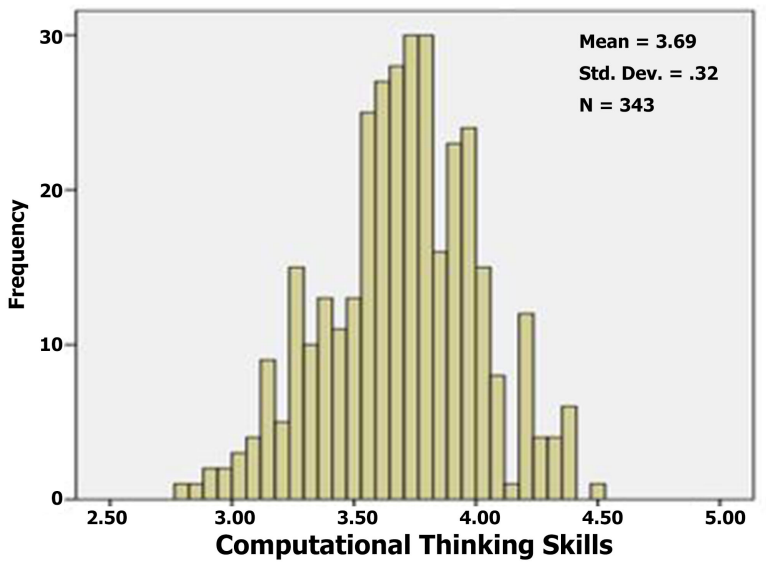

Figure 1. Normality test for computational thinking skills test

\subsection{Level of Computational Thinking among Students}

This study examined several elements of computational thinking: problem solving, cooperative learning and critical thinking, creativity, and algorithmic thinking. The results show that students' computational thinking techniques are at a high level $(\mathrm{M}=3.69, \mathrm{SD}=0.32)$. Table 3 shows that students' problem-solving techniques $(\mathrm{M}=3.80, \mathrm{SD}=0.38)$, creativity techniques $(\mathrm{M}=3.80, \mathrm{SD}=0.47)$, and algorithmic thinking techniques $(\mathrm{M}=3.70, \mathrm{SD}=0.49)$ are at a high level whereas their cooperative learning techniques and critical thinking $(\mathrm{M}=3.16, \mathrm{SD}=0.49)$ are at a moderate level.

\subsection{Differences in Students' Computational Thinking Based on Gender}

$\mathrm{Ho}_{1}$ : There is no significant difference in the mean score for computational thinking based on gender.

An independent sample $t$-test analysis was used to identify the differences in computational thinking skills among students based on gender. As Table 4 indicates, a significant difference emerged in the level of computational thinking $(\mathrm{t}=-2.557, \mathrm{p}=0.011)$ between male and female students. Thus, $\mathrm{Ho}_{1}$ is rejected at the level of significance $(\alpha=0.05)$.

Table 3. Levels of computational thinking among students

\begin{tabular}{cccc}
\hline Construct & Mean & Standard Deviation & Level \\
\hline Problem Solving & 3.80 & 0.38 & High \\
Cooperative Learning and Critical Thinking & 3.16 & 0.49 & Moderate \\
Creativity & 3.80 & 0.47 & High \\
Algorithmic Thinking & 3.70 & 0.49 & High \\
Computational Thinking & 3.69 & 0.32 & High \\
\hline
\end{tabular}

Table 4. Differences in students' computational thinking based on gender

\begin{tabular}{|c|c|c|c|c|c|}
\hline Construct & Gender & Mean & $\begin{array}{c}\text { Standard } \\
\text { Deviation }\end{array}$ & $\mathrm{t}$ & Sig. \\
\hline \multirow[t]{2}{*}{ Problem Solving } & Male & 3.72 & 0.38 & 2.691 & 0.350 \\
\hline & Female & 3.83 & 0.37 & & \\
\hline \multirow[t]{2}{*}{ Cooperative Learning and Critical Thinking } & Male & 3.12 & 0.54 & 1.023 & 0.066 \\
\hline & Female & 3.18 & 0.47 & & \\
\hline \multirow[t]{2}{*}{ Creativity } & Male & 3.76 & 0.49 & 1.121 & 0.723 \\
\hline & Female & 3.82 & 0.46 & & \\
\hline \multirow[t]{2}{*}{ Algorithmic Thinking } & Male & 3.62 & 0.52 & 2.108 & 0.161 \\
\hline & Female & 3.74 & 0.46 & & \\
\hline \multirow[t]{2}{*}{ Computational Thinking } & Male & 3.63 & 0.32 & 2.557 & 0.011 \\
\hline & Female & 3.72 & 0.31 & & \\
\hline
\end{tabular}


Table 5. Differences in students' computational thinking based on education level

\begin{tabular}{|c|c|c|c|c|c|}
\hline Construct & Education Level & Mean & Standard Deviation & $\mathrm{t}$ & Sig. \\
\hline \multirow[t]{2}{*}{ Problem Solving } & Lower form & 3.78 & 0.41 & 0.703 & 0.086 \\
\hline & Upper Form & 3.81 & 0.35 & & \\
\hline \multirow[t]{2}{*}{$\begin{array}{c}\text { Cooperative Learning and Critical } \\
\text { Thinking }\end{array}$} & Lower form & 3.16 & 0.51 & 0.057 & 0.209 \\
\hline & Upper Form & 3.16 & 0.48 & & \\
\hline \multirow[t]{2}{*}{ Creativity } & Lower form & 3.80 & 0.49 & -0.126 & 0.899 \\
\hline & Upper Form & 3.79 & 0.45 & & \\
\hline \multirow[t]{2}{*}{ Algorithmic Thinking } & Lower form & 3.67 & 0.54 & 0.985 & 0.325 \\
\hline & Upper Form & 3.72 & 0.42 & & \\
\hline \multirow[t]{2}{*}{ Computational Thinking } & Lower form & 3.68 & 0.35 & 0.540 & 0.590 \\
\hline & Upper Form & 3.70 & 0.29 & & \\
\hline
\end{tabular}

\subsection{Differences in Students' Computational Thinking Based on Education Level}

$\mathrm{Ho}_{2}$ : No significant difference in mean score exists in computational thinking based on education level.

An independent sample $t$-test analysis was used to identify the differences in computational thinking skills among students based on their education level. As Table 5 demonstrates, there was no significant difference in the level of computational thinking $(\mathrm{t}=-0.540, \mathrm{p}=0.590)$ between lower form students and upper form students, suggesting that $\mathrm{Ho}_{2}$ is rejected at the level of significance $(\alpha=0.05)$.

\section{Discussion}

\subsection{Levels of Computational Thinking among Students}

Overall, students possess a high level of computational thinking, suggesting that they are able to master computational thinking techniques well, especially problem-solving techniques, creativity techniques, and algorithmic thinking techniques. These findings are in line with those of Korocu [31], who also showed that the level of computational thinking for students is high. Several teaching and learning methods implemented through STEM education involving hands-on activities help stimulate computational thinking skills. These applications of computational thinking skills help train students to think creatively and critically, especially when solving a problem. In addition, students can understand the concepts of learning well if they are able to master and implement computational thinking techniques in the learning process [32]. Thus, students with a high level of computational thinking skills tend to be more creative and think critically when solving difficult problems encountered in daily life.
A high level of mastery in problem-solving skills is very important when solving complex problems. Problemsolving techniques involve the skills to evaluate, understand, and analyze the problems encountered in addition to planning the strategies to resolve the problem $[33,34]$. Therefore, students who master problem-solving techniques will be able to manage and solve complex problems, take risks, and become capable of thinking at a high level in solving problems [11]. In the problem-solving process, possessing a high level of creativity skills enables students to use a variety of ideas and methods to complete tasks and solve problems. According to Kong et al.[35] , the fundamentals of STEM learning, which emphasize finding solutions to real-world problems in daily life activities and environments, can be honed, thereby shaping students' creativity, which is based on existing experience and knowledge. Thus, STEM learning methods can enhance students' creativity in problem solving.

Algorithmic thinking skills are important in developing strategies for solving problems. According to Rodriguez et al. [36], students can understand problems well, but find it difficult to develop appropriate and effective strategies to solve the problems because the algorithmic form of formulas, techniques, rules, or steps must be based on information gathered from two or more similar problems. In this regard, STEM learning methods are able to train and improve the students' algorithmic thinking techniques and, thus, assist them in designing more effective and systematic solutions. Cooperative learning emphasizes the cooperation and active involvement of students in a small group. Cooperative learning techniques encourage collaboration among students with different capabilities in achieving the targets and benefits together [37]. Less skilled individuals are able to develop better understanding and skills than he/she ought to independently through cooperation, guidance or assistance, or an expert or more capable peer [38]. In addition, through cooperative learning, students can be trained in critical thinking that includes the ability to draw conclusions and generalizations, the ability 
to critically evaluate the logic and accuracy of a decision [6], as well as improving communication skill by exchanging ideas among themselves and with their teachers [39]. However, cooperative learning techniques and students' critical thinking are still at a moderate level. Students' interest and attitude toward cooperative learning also play an important role in enhancing their self-efficacy toward cooperative learning. STEM education teaching and learning strategies can help and improve students' abilities, self-efficacy, productivity, and related understanding [40,41]. In addition, student-centric, inquiry-based, and hands-on learning approaches were proven to be effective in boosting students' motivation and their engagement in classroom participation [42]. Thus, positive attitudes and high interest in cooperative learning can stimulate students' ability to master cooperative learning techniques and critical thinking.

\subsection{Students' Computational Thinking Based on Gender and Education Level}

The results highlight significant differences in the level of computational thinking between male and female students, which differs from findings by Chongo et al. [8] and Atmatzidou and Demetriadis [7]. In the current study, the mean score indicates that the level of computational thinking is higher among female students than male students. However, Atmatzidou and Demetriadis [7] reported that females need more time than males to become proficient in skills. In many cases, during training sessions female students required more time to attain the same computational thinking skill level as male students. In addition, according to Weintrop et al. [43], female students have a positive attitude and a higher degree of confidence in computational thinking than male students. Thus, positive attitudes and high self-efficacy motivate students to try new things in solving problems. Furthermore, the attitude of male students toward problem solving using computational skills is still at a moderate level, and they show less interest in trying to solve difficult problems [44].

Based on the results, the level of computational thinking based on students' education level did not show any significant differences. This finding is in line with the findings of Atmatzidou and Demetriadis [7]. In addition, the development of computational thinking skills requires continuous training over time. Indeed, Korucu[31] explained that an individual's level of computational thinking skills can be influenced by the duration of the possession of technology. In addition, Korucu[31] and Grover et al. [45] stated that students who possess a technology device for a longer period have a higher level of computational skills. Hence, exposure to the controlled use of technology is one of the appropriate forms of training in developing computational thinking skills regardless of education and age. As such, it is the teacher's responsibility to discover, promote, and fully utilize technology in teaching and learning activities to familiarize students with the use of technology. Such an emphasis on computational skills in the teaching and learning process can enhance students' computational thinking skills.

\section{Conclusions}

This research examines high school students' computational thinking and the differences is such thinking in terms of gender and education level. Students have a high level of computational thinking in problem solving, creativity, and algorithmic thinking whereas the level of mastery for cooperative learning and critical thinking is at the medium level. The study also found that significant differences in the level of computational thinking occurred between the genders, but there was no significant difference based on education level.

The rapid growth of the digital world has made a huge impact on the education system in producing globally competitive and skilled workers. Therefore, $21^{\text {st }}$-century skills, especially computational thinking skills, are a necessity in the current era. To ensure that computational thinking skills can be improved, teaching and learning processes need to be designed in a more direct and detailed way to become more meaningful. To ensure that the components of computational thinking are consistently implemented, assessment-based learning activities are required. A proper and well-planned assessment ensures a successful integration of computational skills within teaching and learning processes. The findings of this research imply that students have high levels of computational thinking skills. As such, the Ministry of Education Malaysia (MOE) can leverage this information to introduce innovation for education in Malaysia. This study is also intended to serve as a guide for educators, especially STEM teachers, in generating ideas to incorporate computational thinking in teaching and learning processes. The dynamic involvement of students in solving problems through learning activities not only helps them master the concepts and theories quickly and easily, but also promotes their interest in STEM education.

The results of this research only cover a small sample size, so further studies are warranted using a large-scale sample size to obtain more accurate and reliable results. In addition, various activities can be carried out in integrating computational thinking skills within teaching and learning processes, such as unplugged activities, scratch game design, game-based learning, and problem-based learning. Future research should determine the extent to which such teaching and learning activities involve active learning that can support the process of integrating computational thinking skills into STEM education. Qualitative research, such as by conducting interviews, can also be conducted to gain feedback from teachers and students on their understanding and knowledge of computational thinking. 


\section{Acknowledgements}

This research was partially supported by the Faculty of Education, Universiti Kebangsaan Malaysia Fund under the Dana FPEND 1 (Reference Number: 24530974).

\section{REFERENCES}

[1] K. Schwab. The Fourth Industrial Revolution, Penguin, UK, 2016.

[2] M. S. Rasul, L. Halim, Z. Iksan. Using Stem Integrated Approach to Nurture Students' Interest and 21st Century Skills, The Eurasia Proceedings of Educational \& Social Sciences (EPESS), 313-319, 2016.

[3] J. M. Wing. Computational Thinking, In Communications of the ACM, Vol.49, No.3, 33-35, 2006.

[4] A. Yadav, C. Mayfield, N. Zhou, S. Hambrusch. Computational Thinking in Elementary and Secondary Teacher Education, ACM transactions on computing education, Vol.14, No.1, 5-11, 2014.

[5] J. Voogt, P. Fisser, J. Good, P. Mishra, A. Yadav. Computational Thinking in Compulsory Education: Towards an Agenda for Research and Practice, Education and Information Technologies, Vol.20, No.4, 715-728, 2015.

[6] M. Yağc1. A Valid and Reliable Tool for Examining Computational Thinking Skills, Education and Information Technologies, Vol.24, No.1, 929-951, 2018.

[7] S. Atmatzidou, S. Demetriadis. Advancing Studentts' Computational Thinking Skills through Educational Robotics : A Study on Age and Gender Relevant Differences, Robotics and Autonomous Systems, Vol.75, 661-670, 2016.

[8] S. Chongo, K. Osman, N. A. Nayan. Level of Computational Thinking Skills among Secondary Science Students: Variation across Gender and Mathematics Achievement, Science Education International, Vol.31, No.2, 159-163, 2020.

[9] T. Djambong, V. Freiman. Task-based Assessment of Students' Computational Thinking Skills Developed Through Visual Programming or Tangible, 13th International Conference on Cognition and Exploratory Learning in Digital Age (CELDA), 41-51, 2016.

[10] M. Adnan, A. Ayob, O. E. Tek, M. N. Ibrahim, N. Ishak, J. Sheriff. Enhancing Malaysian Human Capital from Early Childhood: A Study in the Feasibility and Integratability of the STEM System in the PERMATA Negara Curriculum, Geografia-Malaysian Journal of Society and Space, Vol.12, No.1, 29-36, 2016.

[11] W. Nor, F. Wan, N. M. Arsad, O. Othman, L. Halim, M. S. Rasul, Z. Iksan. Fostering Students' 21st Century Skills Through Project Oriented Problem Based Learning (POPBL) in Integrated STEM Education Program, Asia-Pacific Forum on Science Learning and Teaching, Vol.17, No.1, 1-18, 2016.

[12] W. W. Siong, K. Osman. Pembelajaran Berasaskan Permainan Dalam Pendidikan STEM dan Penguasaan
Kemahiran Abad Ke-21, Politeknik \& Kolej Komuniti Journal of Social Sciences and Humanities, Vol.3, No.1, 121135,2018

[13] A.-N. Lay, K. Osman. Developing $21^{\text {st }}$ Century Skills through a Constructivist-Conctructionist Learning Environment, K-12 STEM Education, Vol.3, No.2, 205-216, 2017.

[14] N. M. Nordin, K. Osman. (2018). Students' Generated Animation: An Innovative Approach to Inculcate Collaborative Problem Solving (Cps) Skills in Learning Physics, Journal of Education in Science, Environment and Health (JESEH), Vol.4, No.2, 206-226, 2018.

[15] C. Selby, J. Woollard. CT: The Developing Definition, Online available from https://eprints.soton.ac.uk/356481/

[16] V. Barr, C. Stephenson. Bringing Computational Thinking to $\mathrm{K}-12$ : What is Involved and what is The Role of The Computer Science Education Community? ACM Inroads, Vol.2, No.1, 48-54, 2011.

[17] ISTE. Computational Thinking Leadership Toolkit, Online available from https://www.iste.org/explore/Solutions/Com putational-thinking-for-all

[18] S. Gelbal. Problem Solving, Hacettepe University Journal of Education, No.6, 167-173, 1991.

[19] R. E. Mayer. Cognitive, Metacognitive, and Motivational Aspects of Problem Solving, Instructional Science, Vol.26, No.1-2, 49-63, 1998.

[20] W. Brown. Introduction to Algorithmic Thinking, Online available from https://raptor.martincarlisle.com/Introductio $\mathrm{n} \% 20$ to\%20Algorithmic\%20Thinking.doc

[21] Z. Katai. The Challenge of Promoting Algorithmic Thinking of Both Sciences and Humanities Oriented Learners, Journal of Computer Assisted Learning, Vol.31, No.4, 287-299, 2015 .

[22] D. F. Halpern. Thoughts and Knowledge: An Introduction to Critical Thinking, Lawrence Erlbaum Associates, New Jersey-London, 1996.

[23] Ö. C.. Bökeoğlu, K. Yılmaz. The Relationship between Attitudes of University Students towards Critical Thinking and Research Anxieties, Educational Administration: Theory and Practice, No.41, 47-67, 2005.

[24] S. M. Özdemir. Assessing University Students' Critical Thinking Skills for Some Variables, the Journal of Turkish Educational Science, Vol.3, No.3, 1-17, 2005.

[25] R. E. Slavin. Cooperative Learning: Theory Research and Practice, Englewood Cliffs, Rentice Hall, 1980.

[26] O. Korkmaz. A Validity and Reliability Study of the Online Cooperative Learning Attitude Scale. Computers \& Education, No.59, 1162-1169, 2012.

[27] O. Korkmaz, Recep Çakir, M. Y. Özden. A Validity and Reliability Study of the Computational Thinking Scales (CTS), Computers in Human Behavior, Vol.72, 558-569, 2017.

[28] R. J. Sternberg, T. I. Lubart. The Concept of Creativity: Prospects and Paradigms, Cambridge University Press, Cambridge, 1999. 
[29] S. Lapammu, Z. Mahamod. The Level of Knowledge, Attitudes, and Readiness Form 4 Students to The Using of Virtual Learning Environment VLE Frog in Malay Language Learning, Malay Language Education Journal-MyLEJ, Vol.8, No.1, 53-62, 2018.

[30] J. R. Freankel, N. E. Wallen, H. H. Hyun. How to Design and Evaluate Research in Education, Mac Graw Hill, New York, 2009.

[31] A. T. Korucu. Examination of the Computational Thinking Skills of Students, Journal of Learning and Teaching in Digital Age, Vol.2, No.1, 11-19, 2017.

[32] L. Gouws, K. Bradshaw, P. Wentworth. First Year Students Performance in a Test for Computational Thinking, SAICSIT'13: Proceeding of The South African Institute for Computer Scientists and Information Technologies Conference. 271-277, 2013.

[33] P. P. Heppner, C. J. Krauskopf. The Integration of Personal Problem Solving Processes Within Counseling Counsel, Psychologist, No.15, 371-447, 1987.

[34] P. P. Heppner, L. Reeder. The Relationship Between Problem Solving Self-Appraisal and Psychological Adjustment, Cognitive Therapy and Research, Vol.9, No.4, 415-427, 1983.

[35] S. Kong, M. M. Chiu, M. Lai. A Study of Primary School Students' Interest, Collaboration Attitude, and Programming Empowerment in Computational Thinking Education, Computers \& Education, No.127, 178-189, 2018.

[36] B. Rodriguez, S. Kennicutt, C. Rader, T. Camp. Assessing Computational Thinking in Cs Unplugged Activities, SIGCSE, 501-506, 2017.

[37] D. W. Johnson, R. T. Johnson. An Educational Psychology Success Story: Social Interdependence Theory and Cooperative Learning, Educational Researcher, Vol.38,
No.5, 365-379, 2009.

[38] L. Vygotsky. Mind in Society: The Development of Higher Psychological Processes, Harvard University Press, United Stated, 1978.

[39] J. Young-Sik, S. Young-Hoon. The Effect of Network-Based PUMA Teaching-Learning Model on Information Literacy, Computational Thinking and Communication Skills, Universal Journal of Educational Research, Vol.7, No.5A, 103-113, 2019.

[40] A.-N. Lay, K. Osman. Developing $21^{\text {st }}$ Century Chemistry Learning through Designing Digital Games, Journal of Education in Science, Environment and Health (JESEH), Vol.4, No.1, 81-92, 2018.

[41] N. Khalil, K. Osman. STEM-21CS Module: Fostering $21^{\text {st }}$ Century Skill through Integrated STEM, K-12 STEM Education, Vol.3, No.3, 225-233, 2017.

[42] A. Saad. Students' Computational Thinking Skill through Cooperative Learning Based on Hand-on, Inquiry-based, and Student-centric Learning Approaches, Universal Journal of Educational Research, Vol.8, No.1, 290-296, 2020.

[43] D. Weintrop, K. Orton, M. Horn, E. Beheshti, L. Trouille, K. Jona, U. Wilensky. Outcomes of Bringing Computational Thinking into STEM Classrooms. Online available from https://ccl.northwestern.edu/2015/Weintrop_et_al_AERA_ 2015.pdf

[44] N. Ngah, \& E. Zakaria. Keupayaan Pelajar Dalam Menjana Masalah, Menyelesaikan Masalah Matematik dan Sikap Pelajar Terhadap Penyelesaian Masalah, Jurnal Pendidikan Matematik, Vol.4, No.1, 1-16, 2016.

[45] S. Grover, R. Pea, S. Cooper. Designing for Deeper Learning in a Blended Computer Science Course for Middle School Students, Computer Science Education, Vol.25, No.2, 199237, 2015. 